University of Wollongong

Research Online

Australian Institute for Innovative Materials -

Papers

Australian Institute for Innovative Materials

$1-1-2013$

\title{
Manganosite-microwave exfoliated graphene oxide composites for asymmetric supercapacitor device applications
}

\author{
Dennis Antiohos \\ University of Wollongong, dennisa@uow.edu.au \\ Kanlaya Pingmuang \\ Chiang Mai University, kp660@uowmail.edu.au \\ Mark Romano \\ University of Wollongong, mromano@uow.edu.au \\ Stephen Beirne \\ University of Wollongong, sbeirne@uow.edu.au \\ Tony C. Romeo \\ University of Wollongong, tromeo@uow.edu.au
}

See next page for additional authors

Follow this and additional works at: https://ro.uow.edu.au/aiimpapers

Part of the Engineering Commons, and the Physical Sciences and Mathematics Commons

Research Online is the open access institutional repository for the University of Wollongong. For further information contact the UOW Library: research-pubs@uow.edu.au 


\title{
Manganosite-microwave exfoliated graphene oxide composites for asymmetric supercapacitor device applications
}

\begin{abstract}
Graphene based materials coupled with transition metal oxides are promising electrode materials in asymmetric supercapacitors owing to their unique properties which include high surface area, good chemical stability, electrical conductivity, abundance, and lower cost profile over time. In this paper a composite material consisting of graphene oxide exfoliated with microwave radiation ( $\mathrm{mw}$ rGO), and manganosite $(\mathrm{MnO})$ is synthesised in order to explore their potential as an electrode material. The composite material was characterised by scanning electron microscopy (SEM), X-ray diffraction (XRD), Xray photoelectron spectroscopy (XPS), and Raman spectroscopy. Cyclic voltammetry (CV) and electrochemical impedance spectroscopy (EIS) were used to explore the process occurring at the electrode/electrolyte interface. Long term cyclability and stability were investigated using galvanostatic charge/discharge testing. From the resulting analysis, an asymmetric supercapacitor was constructed with the best composite containing $90 \% \mathrm{MnO}-10 \% \mathrm{mw} \mathrm{rGO}(\mathrm{w} / \mathrm{w})$. The device exhibited a capacitance of $0.11 \mathrm{~F} / \mathrm{cm} 2(51.5 \mathrm{~F} / \mathrm{g}$ by mass) and excellent capacity retention of $82 \%$ after 15,000 cycles at a current density of $0.5 \mathrm{~A} / \mathrm{g}$.
\end{abstract}

\section{Keywords}

exfoliated, applications, microwave, device, graphene, supercapacitor, asymmetric, composites, oxide, manganosite

\section{Disciplines}

Engineering | Physical Sciences and Mathematics

\section{Publication Details}

Antiohos, D., Pingmuang, K., Romano, M. S., Beirne, S., Romeo, T., Aitchison, P., Minett, A., Wallace, G., Phanichphant, S. \& Chen, J. (2013). Manganosite-microwave exfoliated graphene oxide composites for asymmetric supercapacitor device applications. Electrochimica Acta, 101 99-108.

\section{Authors}

Dennis Antiohos, Kanlaya Pingmuang, Mark Romano, Stephen Beirne, Tony C. Romeo, Phil Aitchison, Andrew I. Minett, Gordon G. Wallace, Sukon Phanichphant, and Jun Chen 


\title{
Manganosite - microwave exfoliated graphene oxide composites
}

\section{for asymmetric supercapacitor device applications.}

\author{
Dennis Antiohos ${ }^{1}$, Kanlaya Pingmuang $^{2}$, Mark Romano $^{1}$, Stephen Beirne ${ }^{1}$, Tony Romeo ${ }^{1}$, Phil \\ Aitchison $^{3}$, Andrew Minett ${ }^{4}$, Gordon Wallace ${ }^{1}$, Sukon Phanichphant ${ }^{2}$, Jun Chen $^{1 *}$ \\ ${ }^{1}$ Intelligent Polymer Research Institute ARC Centre of Excellence for Electromaterials \\ Science, University of Wollongong, NSW, 2522, Australia \\ ${ }^{2}$ Materials Science Research Centre, Faculty of Science, Chiang Mai University, Chiang Mai \\ 50200, Thailand \\ ${ }^{3}$ CAP-XX Australia Pty Ltd, Lane Cove, NSW, 2066, Australia \\ ${ }^{4}$ School of Chemical and Biomolecular Engineering, University of Sydney, NSW, 2006,
} Australia

\begin{abstract}
Graphene based materials coupled with transition metal oxides are promising electrode materials in asymmetric supercapacitors owing to their unique properties which include high surface area, good chemical stability, electrical conductivity, abundance, and lower cost profile over time. In this paper a composite material consisting of graphene oxide exfoliated with microwave radiation (mw rGO), and manganosite $(\mathrm{MnO})$ is synthesised in order to explore their potential as an electrode material. The composite material was characterised by scanning electron microscopy (SEM), x-ray diffraction (XRD), x-ray photoelectron spectroscopy (XPS), and Raman spectroscopy. Cyclic voltammetry (CV) and electrochemical impedance spectroscopy (EIS) was used to explore the process occurring at the electrode / electrolyte interface. Long term cyclability and stability was investigated using galvanostatic
\end{abstract}


charge / discharge testing. From the resulting analysis, an asymmetric supercapacitor was constructed with the best composite containing 90\% MnO- 10\% mw rGO (w/w). The device exhibited a capacitance of $0.11 \mathrm{~F} / \mathrm{cm}^{2}$ (51.5 F/g by mass) and excellent capacity retention of 82\% after 15000 cycles at a current density of $0.5 \mathrm{~A} / \mathrm{g}$.

Key Words: microwave exfoliated graphene oxide, manganosite, and asymmetric supercapacitor.

*Corresponding author: Intelligent Polymer Research Institute, ARC Centre of Excellence for Electromaterials Science, University of Wollongong, NSW, 2522, Australia. E-mail junc@uow.edu.au; and Materials Science Research Centre, Faculty of Science, Chiang Mai University, Chiang Mai 50200, Thailand. Email: sphanichphant@yahoo.com. 


\section{Introduction}

Within the last decade, there has been an increased effort in the development of new hybrid energy storage devices that possess both high energy and high power density which are beneficial for creating more energy efficient storage and delivery [1]. Such systems will find use in hybrid electric vehicles, mobile electronic devices, memory back up systems and industrial equipment that relies on long cycle-life times and uninterruptable power supply [14]. Asymmetric supercapacitors are promising hybrid energy storage devices as they are able to provide a wider operating voltage at higher energy compared to symmetric capacitors [5]. Such supercapacitors are comprised of an anode that is usually an activated carbon, while the cathode is generally a composite consisting of a carbon material and transition metal oxide. Asymmetric supercapacitors make use of the different potential windows in the anode and cathode leading to an increased operational voltage of the aqueous electrolyte in the cell meaning that interfacial capacitance, energy and power density are maximised [5]. Examples include the use of an activated carbon anode while the cathode consists of a composite containing carbon material and transition metal oxide, with these materials being considered promising due to their availability, cost effectiveness and friendly environmental nature [6, 7].

Graphene is a one-atom thick, two-dimensional (2D) material composed of $\mathrm{sp}^{2}$ hybridised carbon which is a good candidate for energy storage materials due to its superior electrical conductivity, mechanical properties, thermal conductivity, high surface area, and its minimal cytotoxicity [2, 8]. Graphene nano-sheets were first obtained by mechanical exfoliation ("scotch tape" method) of bulk graphite and by epitaxial CVD [9]. Further developments have led to graphene, and more generally graphene oxide (GO) to be synthesised by several chemical methods like chemical vapour deposition (CVD), micro mechanical exfoliation, epitaxial growth, the creation of colloidal suspensions, and inorganic reactions [9, 10]. 
Chemical means of creating graphene / GO are more viable as these methods are more effective for large-scale manufacturing, leading to the development of devices on a commercial scale. The exfoliation of GO using microwave irradiation is of particular interest as the process can be performed at room temperature, using a conventional microwave leading to a marked volume increase of the GO, forming an extremely porous powder [11]. Manganosite consists of $\mathrm{Mn}^{2+}$ and $\mathrm{O}^{2-}$ molecules forming an octahedral geometry and a cubic crystal structure [12]. It has potential for use in hybrid energy storage devices due to its quasi-reversible electron transfer that provides high pseudo-capacitative energy density [7]. Over the last decade, manganese oxides with different morphologies including rods, nanotubes, and nanowires have been developed and characterised [1, 13, 14]. Currently, some of the most common methods to make manganese oxide compounds is by using hydrothermal synthesis where $\mathrm{MnSO}_{4} \cdot \mathrm{H}_{2} \mathrm{O}, \mathrm{KMnO}_{4}, \mathrm{MnSO}_{4}$ are mixed together under high pressure allowing the precipitate to form $[15,16]$. In our case, the cathode is a composite material consisting of manganosite ( $\mathrm{MnO}$ ) and microwave exfoliated graphene oxide (mw rGO) providing enhanced energy density due to pseudo-capacitative redox processes [5]. The anode is an activated carbon (AC) which due to its formation of many electric double layers, high surface area and good electrical conductivity leads to a high rate capability (fast charge / discharge) [17].

It is also important that research in energy storage and conversion not only focus on improving energy and power density; attention must also be directed into lowering the fabrication costs and maintaining environmental standards so that commercialisation becomes economically viable $[5,18]$. Recently, much time and effort has been employed in developing materials for asymmetric supercapacitors which take into account factors such as fabrication costs, environmental concerns, and scalability. These materials include - C // $\mathrm{RuO}_{2}[19], \quad \mathrm{Ni}-\mathrm{C} / / \quad \mathrm{Ni}(\mathrm{OH})_{2}$ [20], AC // PEDOT [21], $\mathrm{Li}_{4} \mathrm{Ti}_{5} \mathrm{O}_{12}$ // poly(3-(4- 
fluorophenyl)thiophene) [21], $\mathrm{AC} / / \mathrm{K}_{0.27} \mathrm{MnO}_{2} \cdot 0.6 \mathrm{H}_{2} \mathrm{O}$ [22], $\mathrm{AC} / /-\mathrm{Fe}_{3} \mathrm{O}_{4}$ [23], Graphene // $\mathrm{TiO}_{2 \text { [24], }} \mathrm{Fe}_{3} \mathrm{O}_{4} / /$ Graphene [24], $\mathrm{MnO}_{2} / / \mathrm{CNT}$ [25], and $\mathrm{V}_{2} \mathrm{O}_{5}-\mathrm{CNT} / / \mathrm{Li}$ [26].

In this manuscript, we report a hybrid electrode architecture that incorporates $\mathrm{MnO}$ particles onto the active surfaces of an exfoliated GO matrix. For the composite, the microwave exfoliated reduced graphene oxide (mw rGO) nanosheets serve primarily as a high surface area conductive framework providing support for the adherence of $\mathrm{MnO}$ particles. Physical characterisation of the composite electrodes has shown the MnO particles to be dispersed throughout the mw rGO matrix. Testing of varying weight ratios of $\mathrm{MnO}$ and GO revealed that the combination of high surface area and redox phenomena yielded an electrode material that had a high interfacial capacitance of $0.11 \mathrm{~F} / \mathrm{cm}^{2}$ (51.5 F/g by mass of mw rGO, MnO and PTFE binder). The main advantage of the MnO- mw rGO composite material is its significant capacity retention of $82 \%$ over 15000 cycles which is not common for most carbon / metal oxide composites. A recent review of electrochemical performance conducted by $\mathrm{Wu}$ et. al. details various metal oxides and graphene composites where reported capacity retention for Manganese dioxide / graphene sheet composites ranged from 84\%-97\% between 1000 cycles and 5000 cycles respectively $[5,27,28]$. In addition, the interfacial capacitance of $0.11 \mathrm{~F} / \mathrm{cm}^{2}$ is comparable to the required value of interfacial capacitance $>0.10 \mathrm{~F} / \mathrm{cm}^{2}$ for commercial devices used in peak power demands of pulsed loads in battery-powered electronics [29-31].

\section{Experimental}

\subsection{Synthesis of graphene oxide}

Graphene oxide was synthesised using a modified Hummers method as outlined by Marcano et. al. [9]. In detail, $1 \mathrm{~g}$ of graphite powder (Bay Carbon Inc.) was added to $60 \mathrm{ml}$ of concentrated (98\% w/v) $\mathrm{H}_{2} \mathrm{SO}_{4}$ (Univar) and mixed thoroughly for a few minutes. Then $3.5 \mathrm{~g}$ 
of $\mathrm{KMNO}_{4}$ (Sigma-Aldrich) was added in small aliquots so as the temperature did not exceed $100^{0} \mathrm{C}$. This mixture was left stirring overnight for 18 hours. $300 \mathrm{ml}$ to $500 \mathrm{ml}$ of distilled $\mathrm{H}_{2} \mathrm{O}$ is added (ice bath condition) to hydrolyse the intercalation compound that forms graphite oxide. Lastly, 30\% aqueous $\mathrm{H}_{2} \mathrm{O}_{2}$ (Univar) (drop wise, approximately $3 \mathrm{ml}$ ) is added until a complete colour change is observed. The $\mathrm{H}_{2} \mathrm{O}_{2}$ is added after hydrolysis to decompose permanganate ions into manganese (IV) ions where after the manganese (IV) ions are removed by vacuum filtration (PVDF membrane, 0.22 micron pour size) by washing twice each with concentrated (36\% w/v) $\mathrm{HCl}$ (Univar), water, and ethanol. The $\mathrm{HCl}$ ensures no undesirable manganese hydroxides form, which can get trapped in between the graphene / graphite layers [32]. After vacuum filtration the slurry is dried in a vacuum oven overnight at $50^{\circ} \mathrm{C}$. Exfoliated GO (mw rGO) was formed by using a conventional microwave oven (1200 W). After irradiation, the GO glowed red-hot accompanied by fuming and sparking, leading to a remarkable volume expansion caused by the violent expulsion of the volatile species from the interlayer spaces of the graphene intercalation compound [11, 33].

\subsection{Hydrothermal synthesis of manganosite}

The MnO was prepared using a hydrothermal synthesis method at the Materials Science Research Centre, Faculty of Science, Chiang Mai University. Potassium permanganate $\left(\mathrm{KMnO}_{4}, 97 \%\right.$ Aldrich, USA) and Manganese sulfate $\left(\mathrm{MnSO}_{4}, 97 \%\right.$ Sigma, USA) were prepared by dissolving in deionised water as $0.1 \mathrm{M}$ and $0.6 \mathrm{M}$, respectively. Mixing was accomplished by drop-wise addition of $100 \mathrm{ml} \mathrm{KMnO}_{4}$ solution into $100 \mathrm{ml}$ of $\mathrm{MnSO}_{4}$ solution while stirring. The mixed solution was transferred into a Teflon-lined stainless steel autoclave. The hydrothermal synthesis carried out at $140{ }^{\circ} \mathrm{C}$ for $12 \mathrm{~h}$. After the reaction was complete, the autoclave was cooled down to room temperature. The black product was washed with deionised water and ethanol, filtered and then dried at $60{ }^{\circ} \mathrm{C}$ for $24 \mathrm{~h}$ [15]. 


\subsection{Fabrication of electrodes}

The fabrication of the working electrode was carried out by employing a similar method to that outlined by Yan et. al. [6]. Different mass ratios of $\mathrm{MnO}$ and mw rGO in ethanol were probe sonicated for 30 minutes. After 30 minutes, PTFE (10 wt. \%) dissolved in ethanol was mixed into the MnO-mw rGO ethanol mixture and sonicated for a further 30 minutes. The resulting solution was then stirred on a hot plate (using a magnetic stirrer) at $60^{\circ} \mathrm{C}$ for approximately 2 hours until the ethanol had sufficiently evaporated and the heat allowed the PTFE to bind the material to form a slurry. The four weight ratios of MnO to mw rGO that where prepared were; 0\% MnO- 100\% mw rGO, 60\% MnO- $40 \%$ mw rGO, 70\% MnO30\% mw rGO, and 90\% MnO- $10 \%$ mw rGO respectively. Each slurry was then spread over a stainless steel mesh using a fine spatula and dried overnight in a vacuum oven at $100^{\circ} \mathrm{C}$. Standardised practices for composite electrode preparation of transition metal oxides involve using a conductive additive and binder to provide a supporting scaffold [34, 35]. MnO by itself is a poor conductor $\left(10^{-9} \mathrm{ohm}^{-1} \mathrm{~cm}^{-1}\right)$ [36], which is why the mw rGO was added to provide a conductive scaffold and enhance charge storage and delivery. A film of $\mathrm{MnO}$ exceeding $90 \%(\mathrm{w} / \mathrm{w})$ under the same fabrication conditions could not be formed.

\subsection{Supercapacitor device fabrication}

For device testing, the positive electrode was made as outlined above in Section 2.3. The negative electrode was made out of commercially purchased activated carbon (VC-72, Cabot). Firstly, the activated carbon was functionalised by mixing a $70 \%(\mathrm{w} / \mathrm{w}) \mathrm{HNO}_{3}$ (Univar) and $98 \%(w / w) \mathrm{H}_{2} \mathrm{SO}_{4}$ (Univar) solution in a 3:1 and bath sonicated for 2 hours. The resulting material was then washed with deionised water until a neutral $\mathrm{pH}$ was reached. The functionalised activated carbon (FC) was then mixed with a PTFE binder (10\% w/w) (Sigma- 
Aldrich) to form a slurry that was subsequently spread onto a stainless steel current collector. All electrodes had a geometric area of $1 \mathrm{~cm}^{2}$, with an approximate equal mass loading of 4 $\mathrm{mg} / \mathrm{cm}^{2}$. Devices were constructed by sputter coating two pieces of indium tin oxide (ITO) glass with $100 \mathrm{~nm}$ of Pt to help minimise contact resistance. The two electrodes were pressed between the two current collectors with a PVDF separator of thickness 110 microns and 0.22 micron pore size (Millipore ${ }^{\complement}$ - Durapore $\left.{ }^{\circledR}\right)$. A clamp was used to hold the system in place (constant force of $156 \mathrm{~N}$ ), while UV cure glue (Dynman Light Weld) and UV light source (Dynmax Blue Wave 50) was used to seal the cell. Lastly, a small hole was left where 1M $\mathrm{NaNO}_{3}$ in $\mathrm{H}_{2} \mathrm{O}$ was added as the electrolyte via vacuum filling, with the hole being sealed thereafter with UV cure glue.

\subsection{Physical characterisation}

Physical characterisation was achieved by scanning electron microscopy (SEM), x-ray diffraction (XRD) and Raman spectroscopy. SEM was able to show the morphology of the $\mathrm{MnO}$ and mw rGO composite. XRD was employed in order to understand the crystallinity of the structure and what type of manganese material was present. Raman spectroscopy was used to assess the vibrational properties of the hybrid material. SEM and transmitted electron detection (TED) images were obtained from a JEOL JSM-7500FA field emission SEM. For SEM and STEM imaging the accelerating voltage was $5.0 \mathrm{kV}$ and $30 \mathrm{kV}$ respectively with the emission current being set at $10 \mu \mathrm{A}$. Samples for TED imaging were drop cast onto 200 rest copper grids coated with a uniform carbon-layer (EMS, USA). Energy dispersive x-ray (EDS) spectra were taken on a JEOL JSM-6490LA, where the accelerating voltage was $15 \mathrm{kV}$ and the emission current was $19.5 \mu \mathrm{A}$. XRD was carried out on a GBC MMA XRD $(\lambda=1.54$ Á) with the voltage and current kept at $-40 \mathrm{kV}$ and $25 \mathrm{~mA}$ respectively. Raman spectroscopy was carried out on a Jobin-Yvon Horbia 800 using a $632.81 \mathrm{~nm}$ laser. The data analysis was 
carried out using Labspec V.5.45.09 software. X-ray photoelectron spectroscopy (PHOIBOS 100 hemispherical energy analyser from SPECS) was done using Al, Ka radiation (1486.6 eV) in fixed analyser transmission mode.

\subsection{Electrochemical characterisation}

The electrochemical properties of the MnO- mw rGO composites were studied in both two electrode (device) and three electrode systems by cyclic voltammetry (CV) and electrochemical impedance spectroscopy (EIS). The CV response of the electrodes in the three-electrode set-up was measured at $50 \mathrm{mV} / \mathrm{s}$ using an EDAQ AustraliaTM system with EChem V 2 software (ADI Instruments Pty. Ltd) with a potential difference of 1.1 V. All EIS measurements were performed at room temperature where the frequency range spanned 100 $\mathrm{kHz}$ to $0.01 \mathrm{~Hz}$ with an AC amplitude of $10 \mathrm{mV}$ (rms) using a Gamry EIS $3000^{\mathrm{TM}}$ system. The three electrode set-ups for CV and EIS measurements were relative to an Ag/AgCl (aqueous) reference electrode, with a Pt mesh counter electrode $\left(1.7 \mathrm{~cm}^{2}\right)$.

For long-term cyclability of the device, Galvanostatic cycling tests were carried out with a Neware potentiostat, Test Control ${ }^{\mathrm{a}}$ V.5.0 software, able to record a point every $1 \mathrm{~s}$. The potential window studied was between $0 \mathrm{~V}$ and $1.1 \mathrm{~V}$. In all tests, the electrolyte used was aqueous $1 \mathrm{M} \mathrm{NaNO}_{3}$ as it is cheap, non-corrosive and has very good conductivity. Equivalent

circuit modelling and values for $R_{s}, R_{p}, R_{c t}, C_{d l}, C_{f}, f_{p}$ were obtained using ZView ${ }^{\mathrm{TM}} \mathrm{V}$ 3.2, Scribner Associates.

\section{Results \& Discussion}




\subsection{Scanning electron microscopy}

The SEM images shown in Figure 1a and Figure 1b are of the raw GO and mw rGO powders whilst the images of Figure 1c and Figure 1d are of GO and mw rGO that have been drop cast onto a TEM grid. From Figure 1, some qualitative observations can be made. Firstly, in Figure 1a, the SEM is of the GO after it has been washed and dried as outlined in Section 2.1. It can be seen that its structure is very uniform, containing valleys and elevated regions, which reflect vast amounts of sheet stacking. In Figure 1b, after microwave irradiation; the GO expands leading to the development of an accordion type structure that is highly porous, forming an interconnected network with minimal re-stacking [11]. Optical image comparisons are shown in the insets of Figure 1a and Figure 1b. In Figure 1c, the GO that has been drop cast onto a TEM grid, is extremely flat indicating uniform GO sheets. In Figure 1d, the mw rGO was also drop cast onto a TEM grid, with the ensuing images depicting mw rGO sheets that have a crumpled shape. This crumpling effect adds porosity to the system and hence surface area, which could play a key role in the development and preparation of composite electrode materials.

\subsection{Physical characterisation of graphene oxide}

The Raman spectra of GO shown in Figure 2a is characteristic of a $\mathrm{sp}^{2}$ hybridised material that contains defects on the graphene / graphite basal planes. The D band peak of GO is associated with the disorder degree of graphene occurring at $1328 \mathrm{~cm}^{-1}$; while the $\mathrm{G}$ band peak associated with first order scattering of the stretching vibration mode $E_{2 g}$ observed for $\mathrm{sp}^{2}$ carbon domains occurs at $1586 \mathrm{~cm}^{-1}$ [2]. After microwave irradiation, there is a slight shift in both D and G band peaks to $1343 \mathrm{~cm}^{-1}$ and $1591 \mathrm{~cm}^{-1}$ respectively, and the ratio of the G/D band increased from 0.8 to 0.9 . This increase suggests a slight reduction of the GO. A very weak 2D peak is present at $2616 \mathrm{~cm}^{-1}$ which is characteristic of chemically converted graphene oxide as full conversion to pure graphene does not occur [2]. Microwave irradiation 
of the GO led to exfoliation through the removal of volatile species from the interlayer spaces of the graphene intercalation compound $[11,33]$. The XRD spectra of Figure 2b shows the two distinct peaks for GO at $2 \theta=10.2^{\circ}$ and $22.0^{\circ}$, and one distinct peak for mw rGO at $2 \theta=$ $22^{\circ}$. The sharp peak at $10.2^{\circ}$ is characteristic of GO powder that corresponds to an interlayer distance of $0.87 \mathrm{~nm}[37,38]$. The broader peak at $2 \theta=22^{\circ}$ corresponds to the $(002)$ crystal plane of graphite and amorphous carbon [7]. It is clear that after exfoliation using microwave irradiation, the sharp peak at $2 \theta=10.2^{\circ}$ is much more suppressed as a result of the rapid expansion of the GO layers. The X-ray photoelectron spectra (XPS) of the graphene oxide before and after exfoliation (Figure 2c and d) supports the conclusion that some reduction of the GO has occurred after the microwave irradiation. Each of the C1s spectra for GO and mw rGO can be deconvoluted into three peaks which correspond to the following functional groups: $\mathrm{sp}^{2}$ carbon $(\mathrm{C}=\mathrm{C}, 285.0,284.4 \mathrm{eV})$, epoxy / hydroxyl / carbonyl (C-O, C=O, 286.9, $285.4 \mathrm{eV})$, and carboxylates $(\mathrm{O}-\mathrm{C}=\mathrm{O}, 288.4,288.9 \mathrm{eV})$ respectively [9, 37]. The relative abundance of $\mathrm{C}$ and $\mathrm{O}$ for GO was $71.85 \%$ and $26.49 \%$ with similar sized peaks corresponding to a $\mathrm{C} / \mathrm{O}$ ratio of 3:1. While for mw rGO the relative abundance of $\mathrm{C}$ and $\mathrm{O}$ was $92.22 \%$ and $7.53 \%$ with the epoxy / hydroxyl / carbonyl and carboxylate peaks much more depressed than the carbon peak corresponding to a $\mathrm{C} / \mathrm{O}$ ratio of $12: 1$. It must also be noted that the slight shift of the deconvoluted peaks for mw rGO is due to the enhanced regular structure as compared to the GO [9].

\subsection{Physical characterisation of manganosite - microwave graphene oxide composite.}

Manganosites exhibit pseudocapacitative behaviour over small ranges of potentials, through redox processes which contribute electron transfer between the electrode / electrolyte interface. By combining $\mathrm{MnO}$ with mw rGO, composites can be formed that combine both 
faradaic and non-faradic effects enabling a larger energy density to be obtained, while still holding reasonable power density.

In Figure 3a, the SEM image of the MnO particles after hydrothermal synthesis shows large cube type structures that have a porous nature. When the $\mathrm{MnO}$ is imaged at larger magnification (Figure 3b), it can be seen that the particles are comprised of larger spherical platelets and smaller rod-like structures. The $\mathrm{MnO}$ particles have a distribution of sizes ranging from $20 \mathrm{~nm}$ to $1 \mu \mathrm{m}$. To show the distribution of the $\mathrm{MnO}$ in the mw rGO matrix, EDS spectra was recorded on a section of the image (Figure 3c and Figure 3d). It is apparent that there is a good distribution of $\mathrm{MnO}$ as there is significant overlay of $\mathrm{Mn}\left(K_{\alpha}\right)$ lines throughout the composite material, with the lighter regions (approaching white) being more intense. From these qualitative observations, the $\mathrm{MnO}$ particles are well mixed throughout the mw rGO matrix

The $2 \theta$ peaks of $\mathrm{MnO}$ (Figure 4 ) at $35^{\circ}, 41^{\circ}, 59^{\circ}, 70^{\circ}$, and $74^{\circ}$ correspond to the Manganosite type MnO (JCPDS 00-001-1206). When considering the composite MnO- mw rGO, the carbon (002) peak at $26^{\circ}$ along with the $35^{\circ}, 41^{\circ}, 59^{\circ}$ of $\mathrm{MnO}$ are clearly visible. The broad peak of the mw rGO is due to graphene oxide and other amorphous carbons; while the extremely sharp peaks of $\mathrm{MnO}$ are due to good crystallinity of the metal oxide [6, 38].

\subsection{Electrochemical behaviour of $\mathrm{MnO}$ - microwave exfoliated graphene oxide electrodes}

The cyclic voltammograms shown in Figure 5 depicts a comparison of mw rGO, 60\% $\mathrm{MnO}$ 40\% mw rGO, $70 \% \mathrm{MnO}-30 \%$ mw rGO and $90 \% \mathrm{MnO}-10 \%$ mw rGO composite electrodes on a stainless steel mesh current collector. In all cases, the CV obtained are quasirectangular, with distortions also apparent indicating a pseudo capacitance type behaviour 
(mixture of non-faradaic and faradaic responses). The slight kink in the redox peak also observed for the $70 \% \mathrm{MnO}-30 \%$ mw rGO and $90 \% \mathrm{MnO}-10 \%$ mw rGO are thought to be due to faradaic reactions of the $\mathrm{MnO}$ and carbon. A proposed quasi reversible reaction that may account for this is described below;

$$
\mathrm{MnO}+\mathrm{C}^{+}+\mathrm{e}^{-} \leftrightarrow \mathrm{MnOC}
$$

CVs above scan rates of $50 \mathrm{mV} / \mathrm{s}$ (not shown) started to lose their rectangular shape and distort. This distortion can be attributed to ohmic polarisation ( $\mathrm{iR}$ uncompensated) due to increased current at higher scan rates $(\mathrm{i} \sim \mathrm{dc} / \mathrm{dx})$ as well as an RC time constant that is too large for the higher sweep rates used [39]. The largest current and capacitance was obtained for the $90 \%$ MnO- $10 \% \mathrm{mw}$ rGO at $42.5 \pm 9.2 \mathrm{mF} / \mathrm{cm}^{2}$, while the $70 \% \mathrm{MnO}-30 \% \mathrm{mw}$ rGO was $26.6 \pm$ $1.2 \mathrm{mF} / \mathrm{cm}^{2}$. Both the $60 \% \mathrm{MnO}-40 \% \mathrm{mw}$ rGO and pure mw rGO had values of $18.4 \pm 1.1$ $\mathrm{mF} / \mathrm{cm}^{2}$ and $19.1 \pm 0.3 \mathrm{mF} / \mathrm{cm}^{2}$ respectively. The capacitance was calculated at $50 \mathrm{mV} / \mathrm{s}$ according to $\mathrm{C}=\left(\int \mathrm{Idt}\right) /(\mathrm{mV})$, where $\mathrm{I}$ is the response current density $\left(\mathrm{A} / \mathrm{cm}^{2}\right), \mathrm{V}$ is the potential (V), and $\mathrm{m}$ is the mass of the $\mathrm{MnO}$, mw rGO, and PTFE [3]. The capacitance calculations were calculated at a larger scan rate of $50 \mathrm{mV} / \mathrm{s}$ to show a suitable rate capability.

In Figure 6a (experiment conducted at open circuit potential $(\mathrm{OCP}=100 \mathrm{mV})$ ) it can be seen that there is systematic behaviour in the variation of the Nyquist plot as the weight percent of $\mathrm{MnO}$ is increased. The $90 \% \mathrm{MnO}-10 \%$ mw rGO displayed the smallest semi-circle at high frequencies signifying that the kinetics of this system is the fastest with an increase in the semi-circle as the weight percent of MnO decreased. In this system, the semi-circle $\left(R_{c t}\right)$ is likely to represent a couple of processes. (i) Electrolyte resistance and double layer capacitance within the pores of the electrode, which is best modelled by a transmission line model; (ii) Charge transfer resistance associated with equation 1 [40, 41]. The low frequency increase in imaginary impedance looks to be mainly capacitative from double layer charging / 
discharging, and redox processes as the slope is much steeper than the $45^{\circ}$ associated with Warburg diffusion [42] . This result physically speaking is thought to occur due to the MnO particles being large (see Figure 3) which at the high weight ratio of $90 \% \mathrm{MnO}-10 \% \mathrm{mw}$ rGO effectively causes the surface of the electrode to be better interconnected and more mesoporous [43]. At high frequencies, the intercept of the real part of impedance (Z') with the x-axis $R_{s}$ (which represents the resistance of the electrolyte, intrinsic resistance of the substrate and contact resistance) slightly decreases as the weight percent of $\mathrm{MnO}$ increased [6]. This reflects the fact that the wettability of the electrode / electrolyte interface is increased [44].

The imaginary part of capacitance versus frequency (Figure 6b) represents the energy dissipation of the complex part of capacitance, characteristic of an irreversible process, which can lead to the hysteresis of the electrochemical process [6, 39, 41, 45]. The relaxation time constant $\left(\tau_{s}\right)$ can be evaluated from Figure 6b by finding the peak frequency $\left(f_{p}\right)$ of $\operatorname{Im} C(\omega)$, multiplying by $2 \pi$ and inverting. In Figure $6 b$, with the experiment conducted at OCP, the $90 \% \mathrm{MnO}-10 \% \mathrm{mw}$ rGO showed the largest peak frequency. As the weight ratio of $\mathrm{MnO}$ is increased, there is a shift of $f_{p}$ towards higher frequencies (hence lower time constant) due to faster pseudocapacitative effects. The time constant as a function of frequency is shown in the inset of Figure 6b. Refer to Table 1 for $R_{s}$ and $R_{c t}$ as a function of $\mathrm{MnO}$ composition.

\subsection{Asymmetric supercapacitor device testing}

To investigate device performance of our composite material, an asymmetric supercapacitor device was constructed using the $90 \% \mathrm{MnO}-10 \%$ mw rGO as the cathode and functionalised activated carbon (FC) as the anode. Selection of the $90 \% \mathrm{MnO}-10 \%$ mw rGO was based on results from the 3-electrode cell comparisons of varying weight ratios of $\mathrm{MnO}$ and $\mathrm{mw}$ rGO. 
The $90 \%$ MnO- $10 \%$ mw rGO displayed the largest current and superior kinetics due to the enhanced interconnectivity of the $\mathrm{MnO}$ and mw rGO resulting in superior charge storage and delivery properties. The cyclic voltammograms of Figure 7a are of the asymmetric 90\% MnO- 10\% mw rGO // FC device and exhibit rectangular behaviour over a potential window of $1.1 \mathrm{~V}$ indicating very good charging and discharging of the device [46, 47]. The rectangular shape is maintained even up to the high scan rate of $200 \mathrm{mV} / \mathrm{s}$. In Figure $7 \mathrm{~b}$ and Figure 7c, galvanostatic charge / discharge has been employed in order to simulate and understand real world conditions. The charge / discharge curve (Figure 7b) is very symmetrical, with a slight bend / kink of the charging curve due to the asymmetric nature of the device and the fact that some slower redox processes are occurring due to the $\mathrm{MnO}$ [24, 48]. The time difference between charging and discharging gets smaller and smaller as the current is increased from $0.1 \mathrm{~A} / \mathrm{g}$ to $1.0 \mathrm{~A} / \mathrm{g}$; but then nearly goes back to its original time difference when the current is reduced back to $0.1 \mathrm{~A} / \mathrm{g}$. This signifies very good reversibility at different current densities which is useful for real world applications as the system is able to handle different current ranges [49]. In Figure 7c, the interfacial capacitance is computed as a function of cycle number with a step-wise increase in the current every 100 cycles. It can be seen that good stability is achieved at current densities of up to $0.5 \mathrm{~A} / \mathrm{g}$. At higher current densities approaching $1.0 \mathrm{~A} / \mathrm{g}$, the interfacial capacitance decreases rapidly. When the system is switched back to its initial conditions $(0.1 \mathrm{~A} / \mathrm{g})$ at cycles $900-1000$, the total charge is only slightly less (approximately $96 \%$ of the charge) than cycles 1-100, indicating excellent stability. In Figure 7d, galvanostatic charge / discharge was used to plot energy density versus power density. The maximum calculated [39, 50] energy and power densities were 2.6 $\mathrm{W} . \mathrm{h} / \mathrm{kg}$ and $9024 \mathrm{~W} / \mathrm{kg}$ respectively. The increase in the energy at low current density is due to the enhanced utilisation of available electroactive surface area. At these low rates, the electrolyte has time to fully wet all of the available surface area. 
In Figure 8a, the interfacial capacitance is plotted against cycle number showing the capacity retention of our asymmetric device. It can be seen that initially there is a decrease in the interfacial capacitance due to initial activation of the composite material which comprises wetting and changes in volume as the electrolyte is being adsorbed / desorbed into the pores of the material $[46,51]$. Once equilibrium is reached the capacitance stabilises.

After approximately 1000 cycles, the interfacial capacitance rises, reaching a maximum between approximately 3100 and 5800 cycles due to enhanced redox behaviour of the MnO. There is a slight fall away in the interfacial capacitance with a plateau occurring after 9000 cycles due to degradation (caused by changes in volume and the formation of hausmannite (see Figure 9)) [52]. It can be seen that initially the interfacial capacitance was $0.11 \mathrm{~F} / \mathrm{cm}^{2}$ (51.5 F/g equivalent by mass) and after 15000 cycles it was $0.09 \mathrm{~F} / \mathrm{cm}^{2}$ (41.7 F/g equivalent by mass) indicating a capacity retention of $82 \%$. Our interfacial capacitance of $0.11 \mathrm{~F} / \mathrm{cm}^{2}$ also matches the required value of interfacial capacitance $>0.10 \mathrm{~F} / \mathrm{cm}^{2}$ (peak power demands of pulsed loads) for the devices used in battery-powered electronics [29, 30, 53, 54]. Our capacity retention of $82 \%$ is comparable to those of other asymmetric supercapacitors such as $\mathrm{MnO}_{2}$ //AC (96\% retention after 1000 cycles) [55]; $\mathrm{MnO}_{2} / / \mathrm{CNTs} / \mathrm{SnO}_{2}$ (92\% retention after 100 cycles) [56]; and $\mathrm{LiTi}_{2}\left(\mathrm{PO}_{4}\right)_{3}$ (85\% retention after 1000 cycles) [57]. The advantage of our system is the relative abundance and non-toxic nature of graphene and manganese, with the added benefit of no harmful electrolytes being used [58].

In Figure 8b, the Nyquist plot reflects the asymmetric device just as it was made and after 15000 cycles. For the long term galvanostatic charge / discharge, a current density of $0.5 \mathrm{~A} / \mathrm{g}$ was selected based on Figure 7c where $0.5 \mathrm{~A} / \mathrm{g}$ was the maximum current density that showed good stability. In the Nyquist plot of Figure 8b, it can be seen that at high frequencies 
a small semi-circle is observed with the initial part of this semi-circle exhibiting an elongated region. It is thought that there are actually two semi-circles $\left(R_{p}\right.$ and $\left.R_{c t}\right)$ in these regions which are not able to be resolved. The first $R_{p}$, is a smaller semi-circle representing predominately non-faradaic charge transfer effects and some very small irreversible redox processes from functionalisation of the FC anode during charging / discharging [59]. The second $R_{c t}$, a larger semi-circle as a result of faradaic processes arsing from $\mathrm{MnO}$ [60]. It is apparent however that after 15000 cycles the size of the semi-circle is much larger due to an increase in $R_{c t}$ with a decrease in the interfacial capacitance also apparent which is caused by the formation of another manganese compound as discussed below . Accompanied with this, is an increase in $R_{s}$ from $4.5 \Omega$ to $10.0 \Omega$. This occurs because as the device continues to be cycled, some degradation of the composite occurs through volume changes and irreversible redox processes that increase the contact resistance and slow down the electron transfer kinetics, thus reducing the effectiveness of charge storage and delivery [3, 61]. At low frequencies for both plots, the imaginary part of capacitance rapidly rises, indicating good pseudo-capacitative behaviour [52].

To further understand the behaviour of this $90 \%$ MnO- 10\% mw rGO // FC asymmetric device, equivalent circuit modelling (Figure 8b inset) was employed in order to establish values for $R_{s}, R_{p}, R_{c t}, C_{d l}$ and $C_{f}$ before and after long term galvanostatic charge / discharge testing $[62,63]$. The model chosen reflects the 2-electrode device where both the FC and the 90\% MnO-10\% mw rGO must be considered [64]. In the Nyquist plot of Figure 8b, there are thought to be two semi-circles that are not well resolved at the high to middle frequency regime, with pseudocapacitative behaviour extending to the low frequency portion of the spectrum where the imaginary part of capacitance rapidly rises but is not perfectly vertical. These selected components correspond to two constant phase elements $\left(C P E_{d l}\right.$ and $\left.C P E_{f}\right)$ each accompanied with an associated charge transfer resistance that represent non ideal 
behaviour of the two electrodes $[17,62]$. The Warburg element $\left(W_{o}\right)$ was also selected due to the frequency dependence of the porous capacitance and also counter ion diffusion to the electrode surface that balances the charge while faradaic processes are taking place [3]. $R_{S}$ represents the ionic resistance of the electrolyte, the contact resistance between the active materials and current collectors, and the intrinsic resistance of the substrates [61]. Values for $R_{s}, R_{p}, R_{c t}, C_{d l}, C_{f}, f_{p}$, and $\tau(s)$ are outlined in Table 2 below.

In Figure 9, an XRD spectra has been taken on the 90\% MnO- 10\% mw rGO electrode material before and after galvanostatic charge / discharge in order to gauge any changes in the state of $\mathrm{MnO}$. The ensuing analysis uses the peak intensity ratio as described by Bhattacharya et. al. [65]. After 15000 cycles, 86\% of MnO (cubic) was present whilst the remaining $14 \%$ was converted to hausmannite (tetragonal) due to the appearance of main peaks at $2 \theta=32.7,36.2,44.0$, and 60.3 (card no. 00001 1127) which is a mixture of $\mathrm{Mn}^{2+}$ $\mathrm{Mn}^{3+}{ }_{2} \mathrm{O}_{4}$. This result shows that the stability of our MnO- mw rGO composite is very good with the decrease in interfacial capacitance (Figure 8) primarily being as a result of the formation of hausmannite which creates another interface in the system that is not electrochemically active, thus inhibiting charge storage and delivery.

\section{Conclusions}

In summary, we have successfully synthesised GO through a modified Hummer's method and exfoliated the GO using microwave irradiation. The ensuing SEM and STEM images show significantly altered structure that is highly porous forming an interconnected network with minimal re-stacking of the graphene. The XRD confirms the exfoliation of the GO due to the significant decrease of the sharp peak at $2 \theta=10.2^{\circ}$; while XPS spectra confirms that reduction of the GO is apparent due to the much sharper $\mathrm{C}=\mathrm{C}$ at $284.4 \mathrm{eV}$ peak with the 
relative abundance of $\mathrm{C}$ and $\mathrm{O}$ increasing to $92.22 \%$ and $7.53 \%$ respectively. The G/D band ratio of the Raman spectra also increased from 0.8 to 0.9 signifying the GO has somewhat been reduced. The addition of the $\mathrm{MnO}$ particles show that they are dispersed throughout the GO matrix, with the size of the $\mathrm{MnO}$ particles varying from $20 \mathrm{~nm}$ to $1 \mu \mathrm{m}$.

A composite material was made of $\mathrm{MnO}$ and mw rGO with three electrode testing performed in order to gauge which weight ratio of $\mathrm{MnO}$ to $\mathrm{mw}$ rGO would provide that best electrochemical response in terms of capacitance and kinetic behaviour. The results concluded that the $90 \% \mathrm{MnO}-10 \% \mathrm{mw}$ rGO was the best performing material with 0.107 $\mathrm{F} / \mathrm{cm}^{2}$, the most rectangular $\mathrm{CV}$ and smallest charge transfer resistance. This material was then used to make an asymmetric supercapacitor with functionalised activated carbon. Device testing showed that our composite material displayed excellent reversibility when the current density was altered from $0.1 \mathrm{~A} / \mathrm{g}$ to $1.0 \mathrm{~A} / \mathrm{g}$ and then back to $0.1 \mathrm{~A} / \mathrm{g}$. The long term cyclability tests over 15000 cycles was also very good with a capacity retention of $82 \%$ at $0.5 \mathrm{~A} / \mathrm{g}$. XRD showed the amount of $\mathrm{MnO}$ remaining in the device was $86 \%$ while the remaining $14 \%$ was converted to hausmannite after the $15000^{\text {th }}$ cycle.

\section{Acknowledgements}

The authors acknowledge the financial support from the Australian Research Council Discovery (DP0877348) and Linkage Programs (LP0989266), CAP-XX Australia Ltd, and the UoW Electron Microscopy Centre.

\section{References}

[1]. Q. Cheng, J. Tang, J. Ma, H. Zhang, N. Shinya, L.-C. Qin. Carbon, 49(9) (2011) 2917-2925.

[2]. Z.-S. Wu, W. Ren, L. Xu, F. Li, H.-M. Cheng. ACS Nano, (2011) 5463-5471. 
[3]. Z. Fan, J. Yan, T. Wei, L. Zhi, G. Ning, T. Li, F. Wei. Advanced Functional Materials, 21(12) (2011) 2366-2375.

[4]. P.J. Hall, M. Mirzaeian, S.I. Fletcher, F.B. Sillars, A.J.R. Rennie, G.O. Shitta-Bey, G. Wilson, A. Cruden, R. Carter. Energy \& Environmental Science, (2010).

[5]. P.-C. Chen, G. Shen, Y. Shi, H. Chen, C. Zhou. ACS Nano, 4(8) (2010) 4403-4411.

[6]. J. Yan, Z. Fan, T. Wei, W. Qian, M. Zhang, F. Wei. Carbon, 48(2010) 3825-3833.

[7]. Y. Chen, Y. Zhang, D. Geng, R. Li, H. Hong, J. Chen, X. Sun. Carbon, 49(13) (2011) 4434-4442.

[8]. O. Akhavan, E. Ghaderi. ACS Nano, 4(10) (2010) 5731-5736.

[9]. D.C. Marcano, D.V. Kosynkin, J.M. Berlin, A. Sinitskii, Z. Sun, A. Slesarev, L.B. Alemany, W. Lu, J.M. Tour. ACS Nano, 4(8) (2010) 4806-4814.

[10]. C. Hou, Q. Zhang, M. Zhu, Y. Li, H. Wang. Carbon, 49(1) (2011) 47-53.

[11]. B. Tryba, A.W. Morawski, M. Inagaki. Carbon, 43(11) (2005) 2417-2419.

[12]. S.L. Brock, N. Duan, Z.R. Tian, O. Giraldo, H. Zhou, S.L. Suib. Chemistry of Materials, 10(10) (1998) 2619-2628.

[13]. S. Chen, J. Zhu, X. Wu, Q. Han, X. Wang. ACS Nano, 4(5) (2010) 2822-2830.

[14]. G. Yu, L. Hu, M. Vosgueritchian, H. Wang, X. Xie, J.R. McDonough, X. Cui, Y. Cui, Z. Bao. Nano Letters, 11(7) (2011) 2905-2911.

[15]. N. Wang, H. Pang, H. Peng, G. Li, X. Chen. Crystal Research and Technology, 44(11) (2009) 1230-1234.

[16]. C. Siriwong, S. Phanichphant. Materials Letters, 65(12) (2011) 2007-2009.

[17]. B.E. Conway, Electrochemical Supercapacitors: Scientific Fundamentals and Technological Applications. 1999, New York: Kluwer Acedemic / Plenum Publishers.

[18]. P.J. Hall, E.J. Bain. Energy Policy, 36(12) (2008) 4352-4355. 
[19]. Z. Algharaibeh, X. Liu, P.G. Pickup. Journal of Power Sources, 187(2) (2009) 640643.

[20]. N.W. Duffy, W. Baldsing, A.G. Pandolfo. Electrochimica Acta, 54(2) (2008) 535539.

[21]. G.A. Snook, P. Kao, A.S. Best. Journal of Power Sources, 196(1) (2011) 1-12.

[22]. Q. Qu, L. Li, S. Tian, W. Guo, Y. Wu, R. Holze. Journal of Power Sources, 195(9) (2009) 2789-2794.

[23]. X. Du, C. Wang, M. Chen, Y. Jiao, J. Wang. The Journal of Physical Chemistry C, 113(6) (2009) 2643-2646.

[24]. A.K. Mishra, S. Ramaprabhu. The Journal of Physical Chemistry C, 115(29) (2011) 14006-14013.

[25]. H. Jiang, C. Li, T. Sun, J. Ma. Nanoscale, (2011) 807-812.

[26]. M. Sathiya, A.S. Prakash, K. Ramesha, J.M. Tarascon, A.K. Shukla. Journal of the American Chemical Society, 133(40) (2011) 16291-16299.

[27]. C.-T. Hsieh, C.-Y. Lin, J.-Y. Lin. Electrochimica Acta, 56(24) (2011) 8861-8867.

[28]. Y. Qian, S. Lu, F. Gao. Journal of Materials Science, 46(10) (2010) 3517-3522.

[29]. G.G. Blanton, Design Considerations and Characterization of Origami

Electrochemical Capacitors; Massachusetts Institute of Technology, Honours Thesis, 2004

[30]. P. Sharma, T.S. Bhatti. Energy Conversion and Management, 51(12) (2010) 29012912.

[31]. V.V.N. Obreja. Physica E: Low-dimensional Systems and Nanostructures, 40(7) (2008) 2596-2605.

[32]. Hirata, US Patent 6596 396, 2003 Accessed

[33]. E.H.L. Falcao, R.G. Blair, J.J. Mack, L.M. Viculis, C.-W. Kwon, M. Bendikov, R.B. Kaner, B.S. Dunn, F. Wudl. Carbon, 45(6) (2007) 1367-1369. 
[34]. C.-M. Chen, Q. Zhang, M.-G. Yang, C.-H. Huang, Y.-G. Yang, M.-Z. Wang. Carbon, 50(10) (2012) 3572-3584.

[35]. V. Ruiz, C. Blanco, M. Granda, R. Menendez, R. Santamaria. Journal of Electroanalytical Chemistry, 618(2008) 17-23.

[36]. G. Bhide, R. Dani. Physica, 27(9) (1961) 821-826.

[37]. Y. Zhu, M.D. Stoller, W. Cai, A. Velamakanni, R.D. Piner, D. Chen, R.S. Ruoff. ACS Nano, 4(2) (2010) 1227-1233.

[38]. Z. Li, J. Wang, S. Liu, X. Liu, S. Yang. Journal of Power Sources, 196(19) (2011) 8160-8165.

[39]. D. Antiohos, G. Folkes, P. Sherrell, S. Ashraf, G.G. Wallace, P. Aitchison, A.T. Harris, J. Chen, A.I. Minett. Journal of Materials Chemistry, 21(40) (2011) 1598715994.

[40]. S.W. Zhang, G.Z. Chen. Energy Materials: Materials Science and Engineering for Energy Systems, 3(3) (2008) 186-200.

[41]. H. Kurig, A. Janes, E. Lust. Journal of The Electrochemical Society, 157(3) (2010) A272-A279.

[42]. G. Wang, L. Zhang, J. Zhang. Chemical Society Reviews, 41(2) (2012) 797-828.

[43]. M.d.V. M. Pacios, J. Bartroli, M. J. Esplandiu. J. Electroanalytical Chem. , 619620(2008) 117-114.

[44]. S. Bose, T. Kuila, A.K. Mishra, R. Rajasekar, N.H. Kim, J.H. Lee. Journal of Materials Chemistry, 22(3) (2012) 767-784.

[45]. P.L. Taberna, P. Simon, J.F. Fauvarque. Journal of The Electrochemical Society, 150(3) (2003) A292-A300.

[46]. J. Yan, J. Liu, Z. Fan, T. Wei, L. Zhang. Carbon, 50(6) (2012) 2179-2188. 
[47]. H.R. Byon, S.W. Lee, S. Chen, P.T. Hammond, Y. Shao-Horn. Carbon, 49(2) (2010) 457-467.

[48]. C.-Y. Chen, C.-Y. Fan, M.-T. Lee, J.-K. Chang. Journal of Materials Chemistry, 22(2012) 7697-7700.

[49]. S.O. Kasap, Principles of Electronic Materials \& Devices. 3rd ed. 2009, New York: McGraw-Hill.

[50]. H.J. Jong, K. Akiko, M. Kenji, N. Katsuhiko. Journal of The Electrochemical Society, 153(2) (2006) A321-A328.

[51]. C. Yuan, X. Zhang, L. Su, B. Gao, L. Shen. Journal of Materials Chemistry, 19(32) (2009) 5772-5777.

[52]. W. Shi, J. Zhu, D.H. Sim, Y.Y. Tay, Z. Lu, X. Zhang, Y. Sharma, M. Srinivasan, H. Zhang, H.H. Hng. Q. Yan. Journal of Materials Chemistry, 21(10) (2010) 3422-3427.

[53]. Cap-XX Australia, Supercapacitor Product Bulletin; G Series. 2011 http://www.capxx.com/resources/prodspecs/CAP-XX_G_Series_Product_Bulletin_v9.04.pdf. Accessed 04/04/12

[54]. Cap-XX Australia, Supercapacitor Product Bulletin; H Series. 2011 http://www.cap$\underline{\text { xx.com/resources/prodspecs/CAP-XX_H_Series_Product_Bulletin_v9.05.pdf. }}$ Accessed 04/04/12

[55]. H.-Q. Wang, Z.-S. Li, Y.-G. Huang, Q.-Y. Li, X.-Y. Wang. Journal of Materials Chemistry, 20(19) (2010) 3883-3889.

[56]. C. Yu, C. Masarapu, J. Rong, B. Wei, H. Jiang. Advanced Materials, 21(47) (2009) 4793-4797.

[57]. J.-Y. Luo, Y.-Y. Xia. Journal of Power Sources, 186(1) (2009) 224-227.

[58]. M. Pasta, F. La Mantia, L. Hu, H. Deshazer, Y. Cui. Nano Research, 3(6) (2010) 452458. 
[59]. H. Pan, J. Li, Y. Feng. Nanoscale Research Letters, 5(3) (2010) 654-668.

[60]. T.-F. Hsieh, C.-C. Chuang, W.-J. Chen, J.-H. Huang, W.-T. Chen, C.-M. Shu. Carbon, 50(5) (2011) 1740-1747.

[61]. J. Yan, Z. Fan, T. Wei, W. Qian, M. Zhang, F. Wei. Carbon, 48(13) (2010) 38253833.

[62]. A. J. Bard, L.R. Faulkner, Electrochemical Methods: Fundamentals and Applications. 2001: John Wiley \& Sons, Inc.

[63]. J.D. J. Koryta, L. Kavan, Principles of Electrochemistry 2nd Edition. 1993: John Wiley \& Sons Inc.

[64]. L.L. Zhang, X.S. Zhao. Chemical Society Reviews, 38(9) (2009) 2520-2531.

[65]. A.K. Bhattacharya, K.K. Mallick, A. Hartridge. Materials Letters, 30(1) (1997) 7-13. 


\section{Graphical Abstract}
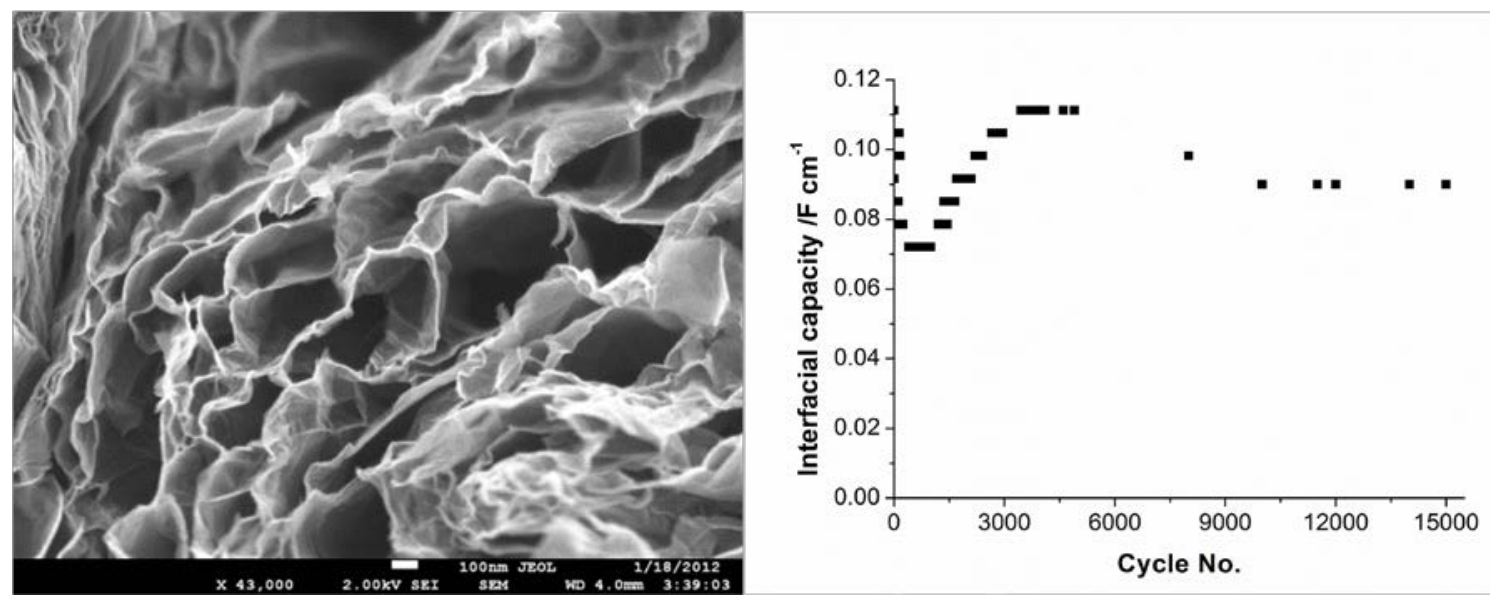

Microwave exfoliated graphene oxide was combined with manganosite into a slurry and formed into a composite cathode material for an asymmetric supercapacitor. The prepared electrode was fabricated into a device with functionalised carbon black as the anode material. The interfacial capacitance was $0.11 \mathrm{~F} / \mathrm{cm}^{2}(51.5 \mathrm{~F} / \mathrm{g})$ with an excellent capacity retention of 82\% over 15000 cycles. 


\section{Table Captions}

Table 1: Comparison of $\mathrm{R}_{\mathrm{s}}$, and $\mathrm{R}_{\mathrm{ct}}$ as the weight ratio of $\mathrm{MnO}$ to GO is increased. Substrate is stainless steel mesh. Values for EIS obtained at open circuit potential.

Table 2: Values for $R_{s}, . R_{p}, R_{c t}, C_{d l}$, and $C_{f}$ obtained from fitting to model. $\tau(\mathrm{s})$ obtained from imaginary part of capacitance verses frequency. 


\section{Figure Captions}

Figure 1: a) SEM image of GO powder after it has been washed and dried as outlined in section 2.1. Inset shows optical image of the GO sample. b) SEM image of mw rGO powder. Inset shows an optical image of the sample after microwave irradiation on the film. c) TED image of GO after it has been drop cast onto a TEM grid. d) TED image of mw rGO after it has been drop cast onto a TEM grid.

Figure 2: (a) Raman spectra of GO and mw rGO powder before and after microwave irradiation. (b) XRD spectra of GO and mw rGO. Comparison of the C1s spectra for (c) GO and (d) mw rGO.

Figure 3: (a) SEM image MnO powder after hydrothermal synthesis. (b) SEM image of MnO powder at higher magnification showing spherical platelets and rod shaped structures. (c) SEM image of 90\% MnO- 10\% mw rGO composite. (d) EDS map of $\mathrm{Mn}\left(K_{\alpha}\right)$ showing the uniformity of distribution in the $90 \% \mathrm{MnO}-10 \% \mathrm{mw}$ rGO composite.

Figure 4: $\mathrm{XRD}$ spectra of $\mathrm{MnO}$, mw rGO, and $\mathrm{MnO}$ - mw rGO at varying weight ratios.

Figure 5: (a) Comparison of CVs for mw rGO, 60\% MnO - 40\% mw rGO, 70\% $\mathrm{MnO}$ - 30\% mw rGO and $90 \% \mathrm{MnO}-10 \%$ mw rGO composite electrodes. Scan rate is at 50 $\mathrm{mV} / \mathrm{s}$. System is three electrode with a Pt mesh counter, and $\mathrm{Ag} / \mathrm{AgCl}$ reference. Electrolyte used is aqueous $1 \mathrm{M} \mathrm{NaNO}$. Material slurry was cast onto stainless steel mesh using a thin spatula.

Figure 6: (a) Nyquist plot comparison of $\mathrm{MnO}$ - mw rGO composite electrodes as the mass percentage of $\mathrm{MnO}$ is changed. (b) Comparison of the imaginary part of capacitance versus frequency for the $\mathrm{MnO}$ - mw rGO composite electrodes. Experiment conducted at open circuit potential. System is three electrode with a Pt 
mesh counter, and $\mathrm{Ag} / \mathrm{AgCl}$. Electrolyte used is aqueous $1 \mathrm{M} \mathrm{NaNO}_{3}$. Material slurry was cast onto stainless steel mesh using a thin spatula.

Figure 7: (a) CV of 90\% MnO-10\% mw rGO // FC asymmetric supercapacitor at $20 \mathrm{mV} / \mathrm{s}$, $50 \mathrm{mV} / \mathrm{s}, 100 \mathrm{mV} / \mathrm{s}$, and $200 \mathrm{mV} / \mathrm{s}$. (b) Galvanostatic charge / discharge tests for varying current rates. (c) Interfacial capacity over 100 cycles as the current density is increased from $0.1 \mathrm{~A} / \mathrm{g}$ to $1.0 \mathrm{~A} / \mathrm{g}$. (d) Ragone plot. Energy and power density values calculated from galvanostatic charge / discharge.

Figure 8: (a) Interfacial capacity versus cycle number at a current density of $0.5 \mathrm{~A} / \mathrm{g}$. (b) Nyquist plots (with inset) of experimental impedance data (scattering dot) and fitting results. (solid line) for 90\% $\mathrm{MnO}$ - 10\% mw rGO // FC asymmetric device in the frequency range from $100000 \mathrm{~Hz}$ to $0.01 \mathrm{~Hz}$ measured before and after 15 000 galvanostatic charge / discharge cycles.

Figure 9: XRD comparison before and after galvanostatic charge / discharge. The current density is $0.5 \mathrm{~A} / \mathrm{g}$ for 15000 cycles. 


\section{Tables}

Table 1: Comparison of $\mathrm{R}_{\mathrm{s}}$, and $\mathrm{R}_{\mathrm{ct}}$ as the weight ratio of $\mathrm{MnO}$ to $\mathrm{mw}$ rGO is increased. Substrate is stainless steel mesh. Values for EIS obtained at open circuit potential.

\begin{tabular}{ccc}
\hline $\begin{array}{c}\text { \% Composition of MnO } \\
\text { : mw rGO (w/w) }\end{array}$ & $\mathrm{R}_{(\mathrm{s})}\left(\right.$ ohm.cm $\left.{ }^{2}\right)$ & $\mathrm{R}_{\text {(ct) }}\left(\mathrm{ohm} . \mathrm{cm}^{2}\right)$ \\
$100: 0$ & $8.4 \pm 0.5$ & $94.0 \pm 5.6$ \\
$60: 40$ & $4.7 \pm 0.2$ & $293.2 \pm 12.5$ \\
$70: 30$ & $7.3 \pm 0.2$ & $174.8 \pm 4.9$ \\
$90: 10$ & $5.2 \pm 0.3$ & $87.6 \pm 5.1$ \\
\hline
\end{tabular}


Table 2: Values for $R_{s}, R_{p}, R_{c t}, C_{d l}$, and $C_{f}$ obtained from fitting to model. $\tau(\mathrm{s})$ obtained from imaginary part of capacitance verses frequency.

\begin{tabular}{cccccccc}
\hline Cycle & $\begin{array}{c}\mathrm{R}_{\mathrm{s}} \\
\left(\mathrm{ohm} . \mathrm{cm}^{2}\right)\end{array}$ & $\begin{array}{c}\mathrm{R}_{\mathrm{p}} \\
\left(\mathrm{ohm} \cdot \mathrm{cm}^{2}\right)\end{array}$ & $\begin{array}{c}\mathrm{R}_{\mathrm{ct}} \\
\left(\mathrm{ohm} \cdot \mathrm{cm}^{2}\right)\end{array}$ & $C_{d l}(\mathrm{~F})$ & $C_{f}(\mathrm{~F})$ & $f_{p}(\mathrm{~Hz})$ & $\tau(\mathrm{s})$ \\
Initial & 4.5 & 5.9 & 18.6 & 0.0014 & 0.0085 & 0.32 & 0.50 \\
$15000^{\text {th }}$ & 10.0 & 18.0 & 39.5 & 0.0013 & 0.0051 & 0.062 & 2.57 \\
\hline
\end{tabular}


Figures



Figure 1: a) SEM image of GO powder after it has been washed and dried as outlined in section 2.1. Inset shows optical image of the GO sample. b) SEM image of mw rGO powder. Inset shows an optical image of the sample after microwave irradiation on the film. c) TED image of GO after it has been drop cast onto a TEM grid. d) TED image of mw rGO after it has been drop cast onto a TEM grid. 

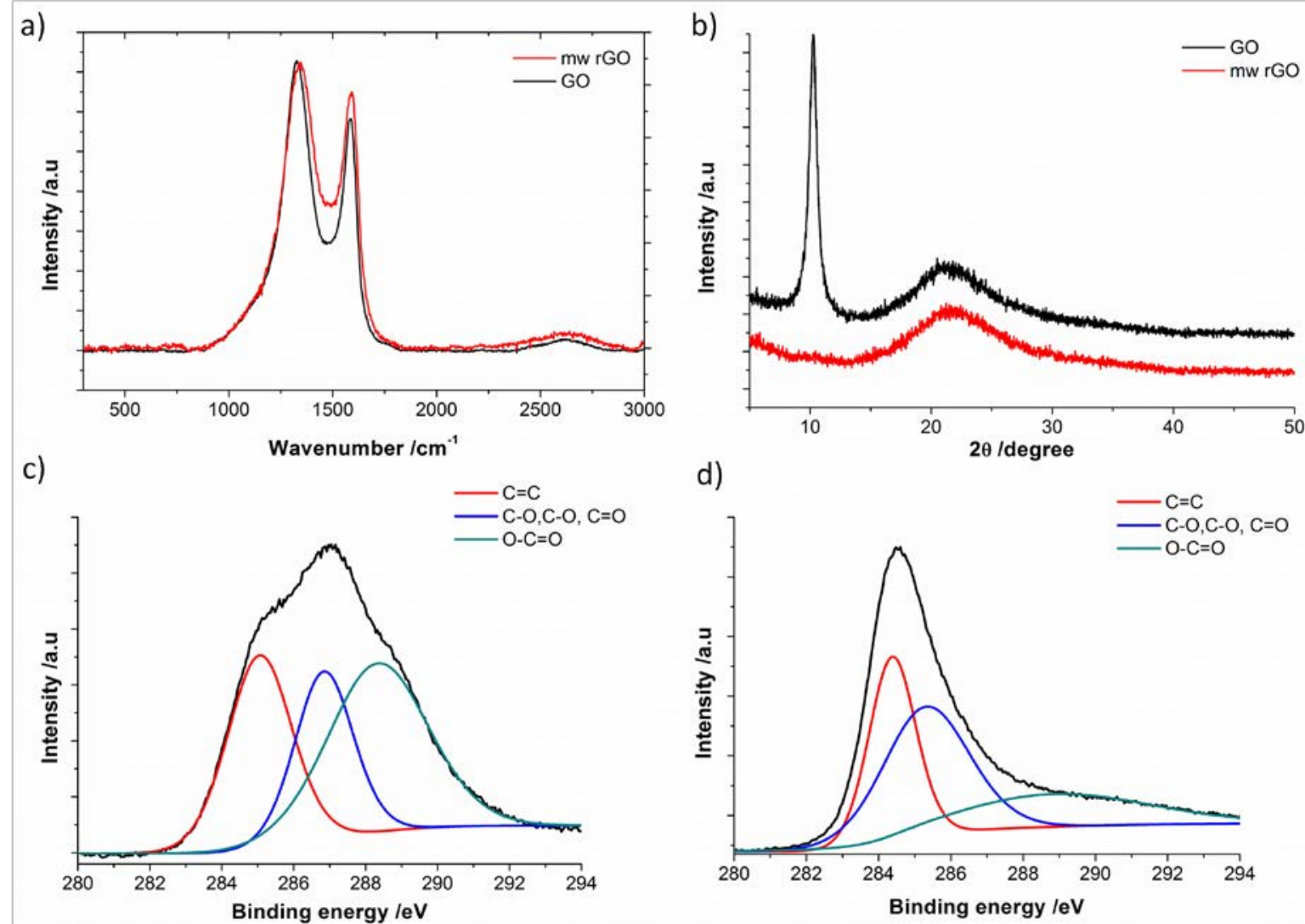

Figure 2: (a) Raman spectra of GO and mw rGO powder before and after microwave irradiation. (b) XRD spectra of GO and mw rGO. Comparison of the C1s spectra for (c) GO and (d) mw rGO. 


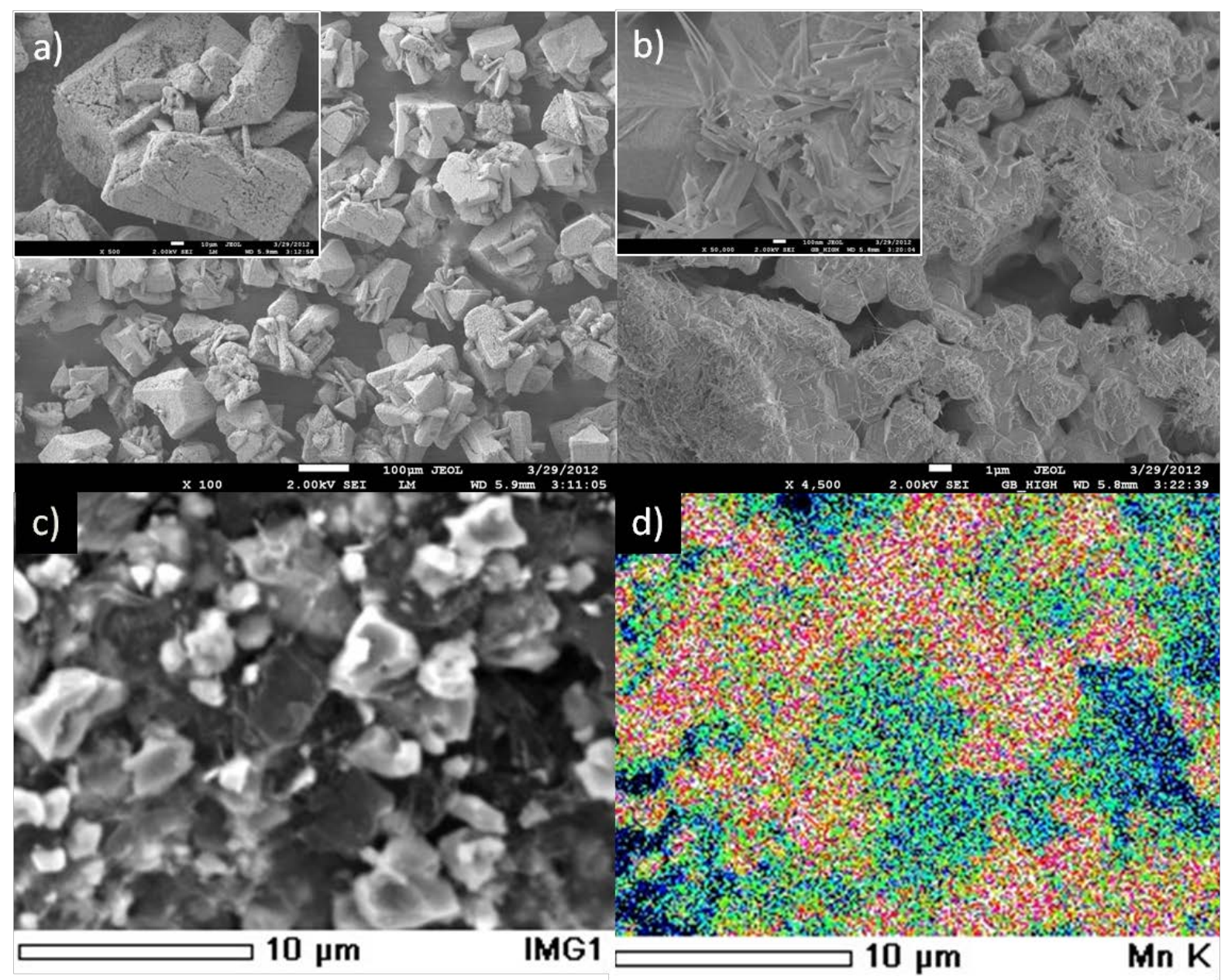

Figure 3: a) SEM image MnO powder after hydrothermal synthesis. (b) SEM image of MnO powder at higher magnification showing spherical platelets and rod shaped structures. (c) SEM image of $90 \% \mathrm{MnO}-10 \%$ mw rGO composite. (d) EDS map of Mn $\left(K_{\alpha}\right)$ showing the uniformity of distribution in the $90 \% \mathrm{MnO}-10 \%$ mw rGO composite. 




Figure 4: XRD spectra of $\mathrm{MnO}$, mw rGO, and $\mathrm{MnO}$ - mw rGO at varying weight ratios. 


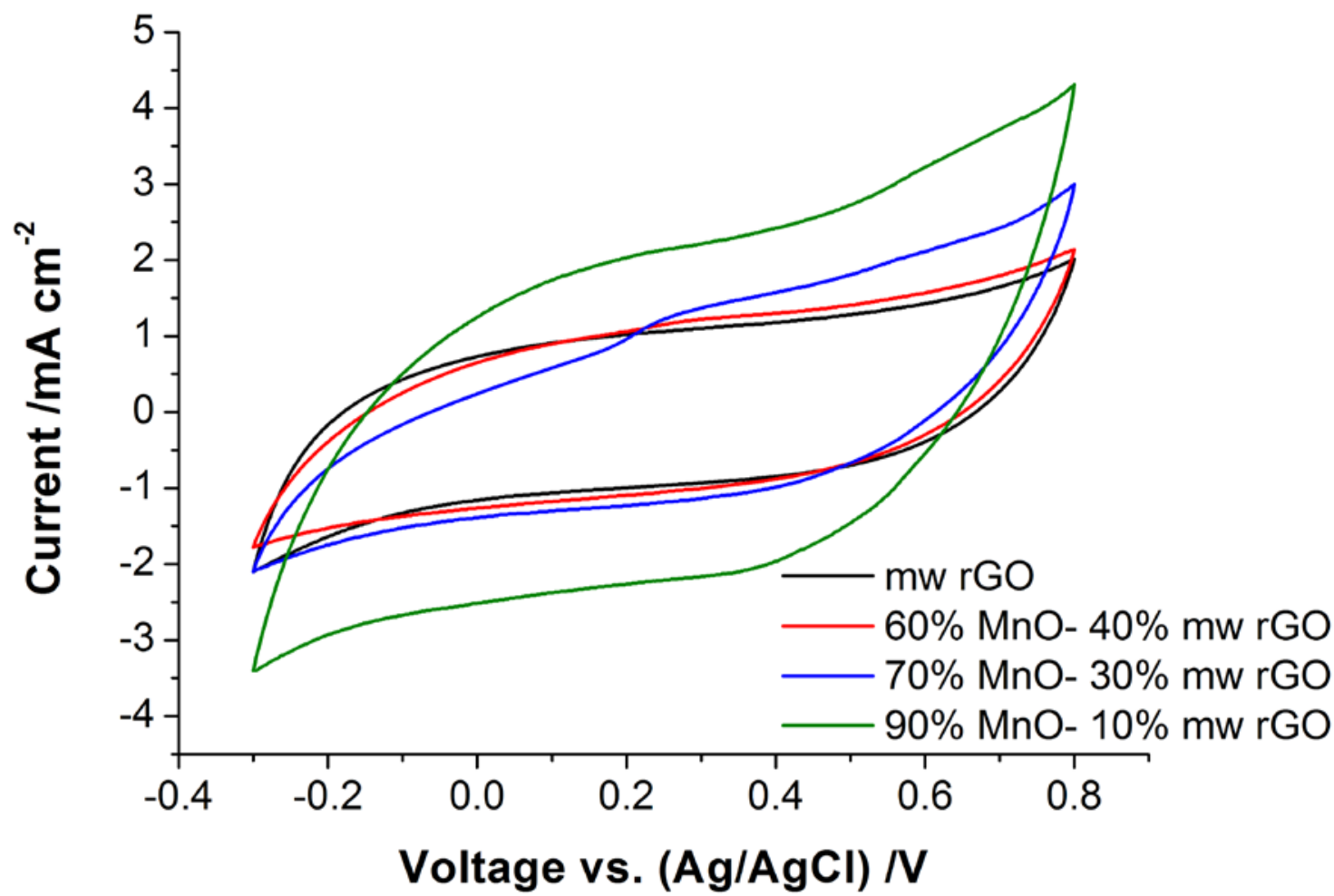

Figure 5: (a) Comparison of CVs for mw rGO, 60\% MnO - 40\% mw rGO, 70\% $\mathrm{MnO}-30 \%$ mw rGO and $90 \% \mathrm{MnO}-10 \%$ mw rGO composite electrodes. Scan rate is at $50 \mathrm{mV} / \mathrm{s}$. System is three electrode with a Pt mesh counter, and Ag/AgCl reference. Electrolyte used is aqueous $1 \mathrm{M} \mathrm{NaNO}$. Material slurry was cast onto stainless steel mesh using a thin spatula. 


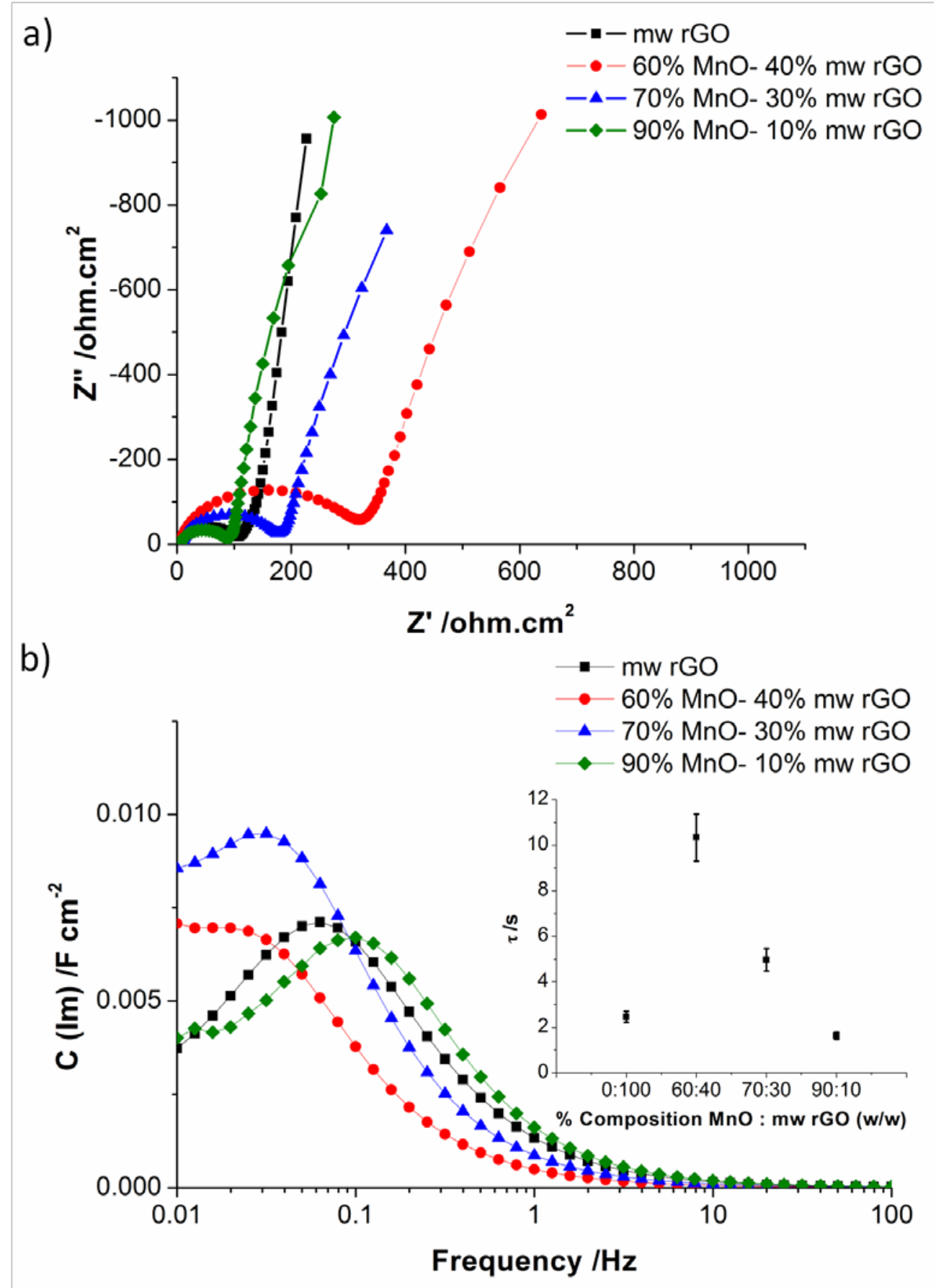

Figure 6: (a) Nyquist plot comparison of $\mathrm{MnO}$ - mw rGO composite electrodes as the mass percentage of $\mathrm{MnO}$ is changed. (b) Comparison of the imaginary part of capacitance versus frequency for the $\mathrm{MnO}$ - mw rGO composite electrodes. Experiment conducted at open circuit potential. System is three electrode with a Pt mesh counter, and Ag/AgCl Electrolyte used is aqueous $1 \mathrm{M} \mathrm{NaNO}$.Material slurry was cast onto stainless steel mesh using a thin spatula. 
a)



c)



b)



d)

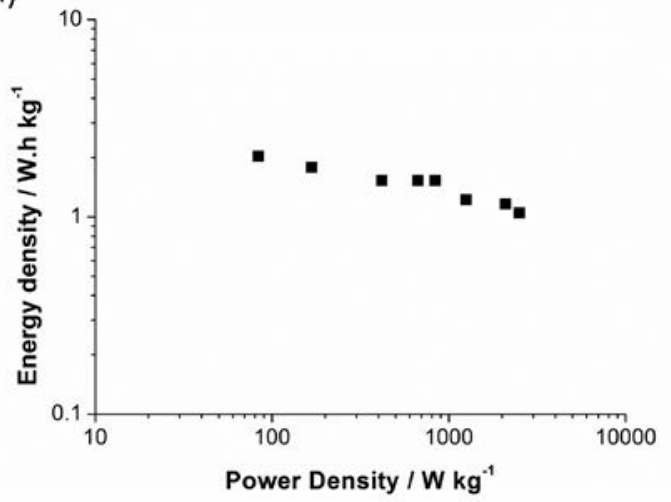

Figure 7: (a) CV of 90\% MnO-mw rGO // FC asymmetric supercapacitor at $20 \mathrm{mV} / \mathrm{s}, 50$ mV/s, $100 \mathrm{mV} / \mathrm{s}$, and $200 \mathrm{mV} / \mathrm{s}$. (b) Galvanostatic charge / discharge tests for varying current rates. (c) Interfacial capacity over 100 cycles as the current density is increased from $0.1 \mathrm{~A} / \mathrm{g}$ to $1.0 \mathrm{~A} / \mathrm{g}$. (d) Ragone plot. Energy and power density values calculated from galvanostatic charge / discharge. 
a)



b)

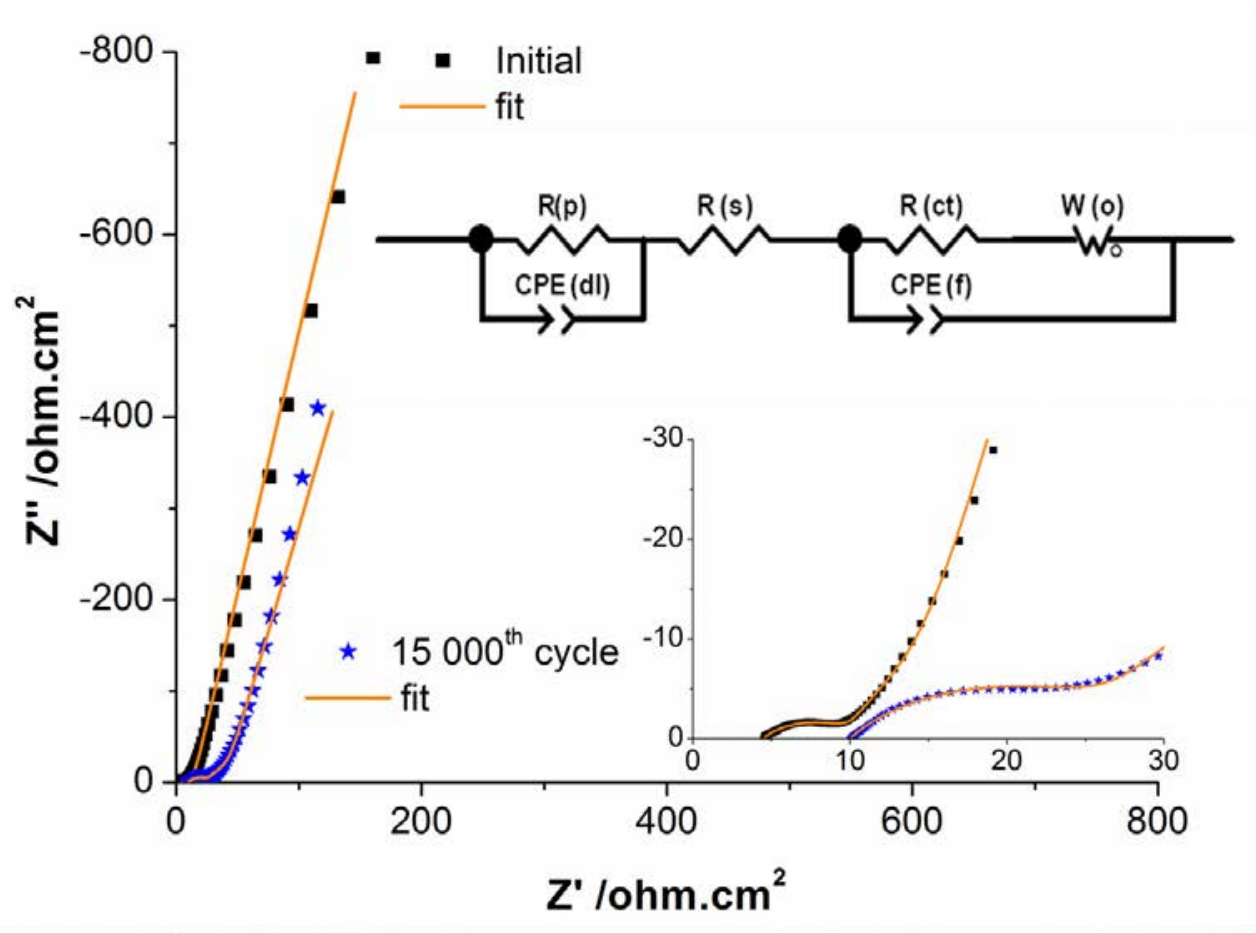

Figure 8: (a) Interfacial capacity versus cycle number at a current density of $0.5 \mathrm{~A} / \mathrm{g}$. (b) Nyquist plots (with inset) of experimental impedance data (scattering dot) and fitting results. (solid line) for $90 \% \mathrm{MnO}-10 \% \mathrm{mw} \mathrm{rGO} / / \mathrm{FC}$ asymmetric device in the frequency range from $100000 \mathrm{~Hz}$ to $0.01 \mathrm{~Hz}$ measured before and after 15000 galvanostatic charge / discharge cycles. 


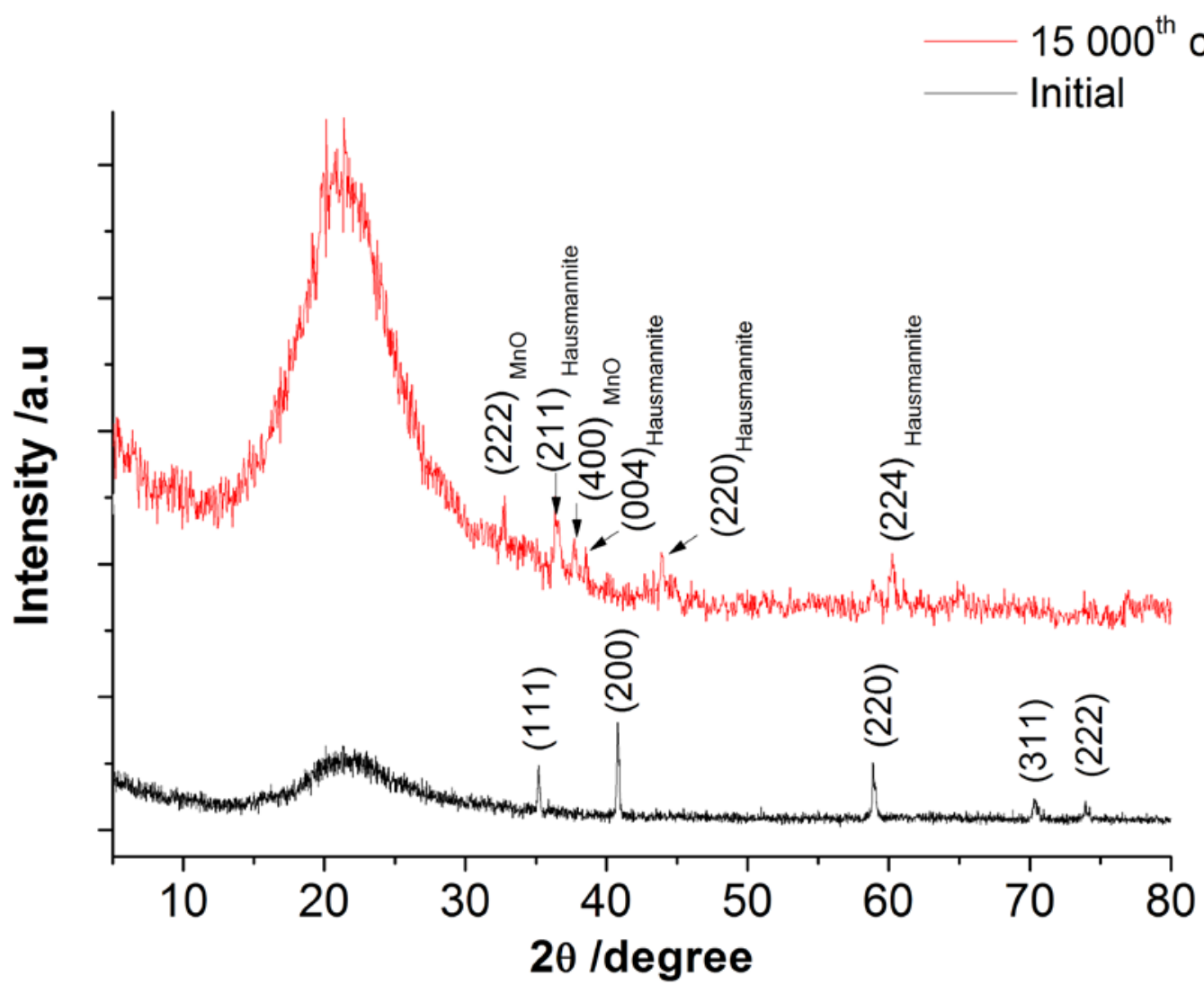

Figure 9: XRD comparison before and after galvanostatic charge / discharge. The current density is $0.5 \mathrm{~A} / \mathrm{g}$ for 15000 cycles. 